\title{
A Case Study on Logistics Services Preferences for Supply Chain Entities in Shandong Province, China
}

Author(s): Woosuk Seo, Seung Bum Ahn

Source: Journal of International Logistics and Trade 2019; 17(2):55-66

Published by: Jungseok Research Institute of International Logistics and Trade, Inha University

DOI: https://doi.org/10.24006/jilt.2019.17.2.055

The Journal of International Logistics and Trade is an official journal published by Jungseok Research Institute of International Logistics and Trade, Inha University, Korea. JILT welcomes manuscripts that advance the practice and science of logistics, trade, and other related fields.

Frequency: Quarterly (March, June, September, December)

Stable URL: https://www.ejilt.org

The Jungseok Research Institute of International Logistics and Trade is a specialized academic research institute representing Inha University and the Inha Foundation in Korea. The institute aims to become a representative institute in Northeast Asia in the research of logistics and trade.

Stable URL: https://jrieng.inha.ac.kr

(C) Copyright. Jungseok Research Institute of International Logistics and Trade.

This is an Open-Access article distributed under the terms of the Creative Commons Attribution NonCommercial License (http://creativecommons.org/licenses/by-nc/4.0/) which permits unrestricted noncommercial use, distribution, and reproduction in any medium, provided the original work is properly cited 


\title{
Journal of
}

\section{International Logistics and Trade}

\section{A Case Study on Logistics Services Preferences for Supply Chain Entities in Shandong Province, China}

\author{
Woosuk Seo*, Seung Bum Ahn \\ Graduate School of Logistics, Incheon National University, Korea
}

\begin{abstract}
ARTICLE INFO
Article history:

Received 19 May 2019

Accepted 30 June 2019

Keywords:

Logistics Services

AHP

Supply Chain Entity

Service Preferences
\end{abstract}

Revision received 30 June 2019

\begin{abstract}
As the Chinese economy has grown rapidly and as its container throughputs has demonstrated a stark increase in recent decades, companies worldwide have developed stronger financial connections with supply chain entities in China, a huge "Production Factory" in the world. This global economic trend arouses significant attention to distinct preference of individual entities in supply chain. The primary goal of the study is to establish statistical understanding on factors of logistics service preferences of each supply chain of each supply chain entity in China, especially Shandong Province. Ultimately, the study aims i) to establish the solid framework for proper evaluation of logistics services in supply chains, ii) to enhance the preferences of logistics services as a differentiating feature on behalf of entities. The study utilizes a holistic approach in analyzing logistics service attributes which affect overall logistics entities in an effort to overcome the limitations of previous studies which failed to provide integrating viewpoint of supply chain entities. In this study, AHP (Analytic Hierarchy Process) method is used as an analysis tool which allows an in-depth examination of the differences between factors and evaluations of customers regarding the logistics service attributes. The results clearly show distinctive service preferences for each four supply chain entities in Shandong Province of China such as 3PLs (forwarder, carrier, and warehouse), Customs (airport, seaport, and bonded area), Market channels (wholesaler, retailer, and e-retailer), and Manufacturers regarding the logistics service attributes.
\end{abstract}

(c) 2019 Jungseok Research Institute of International Logistics and Trade, All rights reserved.

\section{Introduction}

A global logistics industry has grown as a key means to enabling conglomerates to diminish an expenditure of business flow and to cope with dramatic changes in global competition. The demonstrated effectiveness of the logistics industry has led companies to outsource their own logistics functions to professional logistics firms, the so-called 3PLs (forwarder, carrier, and warehouse), and this is affecting plenty of entities in global supply chains.

In general, supply chains are comprised of numerous entities in the transportation of goods and services from origin to destination. It is essential for entities upstream and downstream to choose the best suitable logistics services, which enables better performance of value delivery. Therefore, the use of appropriate supply chains that meet each entity's preferences for logistics service traits provides companies with lots of benefits, such as reduced logistics costs, reliability of service level, proper legislation, shortened order-cycle lengths, credit-to-cash conversions, high reputation, insightful experiences with companies, etc.

\footnotetext{
* Corresponding author: Graduate School of Logistics, Incheon National University,119 Academy-ro, Yeonsu-gu, Incheon, 22012, Republic of Korea; Email: lucas.ws.seo@gmail.com
} 
Furthermore, a continuous increase in container throughputs due to the economic growth in China encourages companies worldwide to make closer connections with supply chain entities in China. The trend necessitates survey research into the preferences of each entity in the supply chain.

In order to deal with this worldwide trend and to provide further insights into the field of business, this study intends to investigate preferred logistics service factors for each supply chain entity in China, focusing on Shandong Province, where many Korean companies are located. The purpose of the study is to suggest a guideline for logistics companies and buyers who are willing to understand the Chinese logistics market and to enter it. The primary method used in the study was the analytic hierarchy process (AHP). AHP evaluation criteria for a hierarchy of upper and lower factors were considered in order to analyze the logistics service preferences of each entity in the supply chain.

Several research papers provided insights into selecting factors for AHP and for structuring the hierarchy of factors and sub-factors in the study. Soh (2010) conceptualized the decision model for evaluating the 3PL selection criteria. Developed were five stages, with each stage composed of a decision hierarchy: finance, service level, relationship, management, and infrastructure. Although these stages were adopted, the paper's exclusive focus on the components of each stage brought about limited results that evaluated only 3PLs.

Expanding the concept and the scope of this study, compared to other studies, more sub-factors were exclusively selected and added in order to appropriately investigate the preferences of each supply chain entity. The extracted sub-factors were based on other preliminary research.

\section{Literature review}

This section is divided in two. The first part of the reviews accounts for the framework and factors previously studied in order to design the questionnaire. The second part of the reviews describes additional factors, particularly taken into account in order to understand supply chains in China and allowing understanding of the more sophisticated service hierarchy and framework, as well as extracted added factors that several entities have focused on.

Logistics outsourcing has been an important part of businesses for numerous organizations, which have focused on improving efficiency and effectiveness of internal and external activities under competitive market conditions (Fachao et al., 2012). Many enterprises have struggled for many years to align their own tactical and strategic business processes with external parties or logistics providers. To accomplish the goal, the establishment of the appropriate indicator system requires descriptive models carrying out qualitative and quantitative analysis as well as decision processes for model selection.

\subsection{Framework for conceptualizing the logistics factors}

There have been many academic approaches toward defining suitable frameworks, as well as determining the parameters, of logistics industries. However, most studies were limited to providing simple lists of decision models through a survey method rather than proposing an integrated framework and viewpoint.

The decision model for evaluating selection criteria conceptualized the practical possibility for the application of framework selection, and developed five stages of the decision hierarchy: finance, service level, relationship, management, and infrastructure (Soh, 2010). That paper structured a decision hierarchy with multi-criteria using fuzzy analytics that supported reasons for, and alternatives to, selecting suitable 3PLs. Also, it reflected the relative importance of service attributes in 3PLs, and suggested a suitable framework with preference criteria. Hence, it showed a structured framework affecting 3PL selection criteria, which implied that certain service attributes were highly correlated in optimal decisions.

3PLs faced with meeting clients' demands need a higher level of customer service at a lower cost. Therefore, many enterprises sought to improve operational efficiency and effectiveness based on previous performance measures. However, only a few enterprises have fully understood the potential of a performance system so far.

At this point, Domingues et al. (2015) constructed a comprehensive performance framework in order to improve operational efficiency and the fulfilment of clients' needs. It represented three layers: the activities dimension, the decision-level dimension, and the different actors dimension. The previous findings from different research or studies in the literature classified each segment to make their own detailed dashboard for further assessment, monitoring, and recommendations, with proposed case studies. However, the results from the case studies were insufficient to represent a comprehensive framework.

Otherwise, Rajesh et al. (2012) provided a sound proposal of a generic framework that helped 3PLs develop and implement a balanced scorecard for their organizations. Different and complicated layers of an organization and work scopes required different measurements of performance in order to sustain competitiveness in the current business climate. This study provided numerous indicators regarding an economic, operational, and strategic scope for better analysis of measures from each perspective in the organization.

Accordingly, this study suggested that 3PL providers take corrective actions; so, it led to a cost-effective solution that delivered better returns on people, processes, customers, and technologies. Through investigation and analysis of numerous scorecards for strategic and operational implementation, the proposed balanced scorecard on 3PLs could 
suggest a clear view of why, what, when, and how to develop and implement performance indications for each strategy from each perspective. The data and results were cropped from Q-sort and Delphi to gather and analyse the dataset.

\subsection{Regional bloc, and trade policies, agreements and programmes}

Although Soh (2010), Domingues et al. (2015), and Rajesh et al. (2012) gave insights into grasping the framework and developing the questionnaire in the present study, the above papers were limited to investigating only 3PLs' preferences, just a single entity of a whole supply chain, and this limitation made some sub-factors ambiguous and insufficient for finding upper factors in other entities, such as retailers, manufacturers, and customs brokers. Besides, the former studies did not present any solid evidence that the developed framework had the practical possibility of being effective to logistics practitioners in China.

An analysis by Chin et al. (2007) was referred to in finding the preferred service traits of Chinese logistics practitioners. That study analyzed the results of a survey questionnaire filled out by logistics service providers in Shanghai, China. It allowed 3PL providers in Shanghai to have more competitiveness while assessing logistics capabilities for better opportunities. The conclusion of the study was that logistics providers in Shanghai have a potential capability to improve their logistics operations and quality of service to meet diverse customer needs. In spite of the necessity for a systematic analysis, a lack of information technology, human resources, expertise, and capital investment discourages a lot of logistics providers from addressing logistical challenges.

Accordingly, this paper aims to make a self-assessment tool to provide some suggestions for the development of Chinese logistics companies. The ultimate goal of the paper is to encourage 3PL providers to develop value-added services for a more comprehensive and integrated service scope. Moreover, the papers reviewed below helped to find sub-factors under the five stages mentioned above (finance, service level, relationship, management, and infrastructure) and which were categorized by Soh (2010).

Finance. It seems clear that the boundary between the concepts of finance and logistics has been blurred for the past few decades. However, people have started to recognize that a strong correlation between finance and logistics services exists. Logistics industries have shown great development in managing the flow of products, services, and information, but they have a tendency to overlook discord between finance and logistics services. Therefore, appropriate measures and examples are necessary between capacity and cost or demand causing operational constraints before yielding profits. The reviewed studies were classified into two cases in the finance section: cost minimization and profit maximization. The first is how to minimize costs when acquiring vessels or warehouse capacity, improving service quality, and mitigating expected operational constraints. The second is how to maximize profits when vessels or space capacity under uncertain demands and delivery-time constraints needs to be considered at the same time. On the other hand, improved operations generate operational efficiency that helps to achieve cost minimization and profit maximization. The key to fine logistics finance lies in understanding how operational constraints can be minimized, and this leads to driving a firm to additional profitability. First, Meng and Wang (2011) pinpointed the liner shipping service network design problem. They took into account practical operating aspects, such as combined hub-and-spoke, multi-port-calling operations, trans-shipment costs, container handling time, and empty container repositioning in order to develop a segment-based path flow for the proposed problem. The result, deriving from realistic Asia-Europe-Oceania shipping operations of a global liner shipping company, was effectively proven and validated. The proposed model incorporated empty container repositioning issues into a cost-effective solution while combining it with cost savings from operations. They believed that these findings could contribute to allocating resources to optimal liner shipping service networks for strengthening cost-effectiveness and efficiency. In the paper, they used optimization solver C-PLEX and mixed-integer linear programming. Additionally, Dong and Jing (2012) came up with a different issue regarding the liner shipping service network design problem. They pinpointed the problem of joint cargo routing and empty container repositioning operations when designing a service network for multiple service routes and vessel deployment. Numerous scenarios and variables were tested in order to minimize total relevant costs related to planning horizons for multiple shipping service routes. The results clearly manifested the superiority of two solution methods over the practical policy. The solutions were two-stage, shortest-path, and two-stage heuristic rules, which incorporated an implementation algorithm in a dynamic system. At this point, Meng and Wang (2011) suggested a view of the liner shipping service network as providing two solutions to optimize problems between cost minimization and performance maximization.

Service level. The role of service level is a simple agreement between the service provider and the customer, quantifying the minimum acceptable service in a business and aiming at improving customer satisfaction in the end. There are many variables that affect service level. Service quality is mostly considered the important aspect that varies the service levels. In this section, research demonstrating which variables affect the service level and its respective quality are introduced, with several examples. Kang and Kim (2009) attempted to develop their own scales to assess the shipping service quality in Korea with the help of previous studies. They focused on reviewing major problems for service operations in the shipping industry. The research proposed a way to scale measurable dimensions and assess the shipping service quality in Korea. The framework proposed by this study may be a good tool to identify the major problems in service operations for shipping service organizations, and offers some insights into how to solve these issues. The proposed framework consists of sub-components affecting each logistics service quality. Koo et al. (2009) incorporated 
Kang and Kim's 2009 evaluation of logistics service quality into a comparative study in order to explore the operations of logistics services from the perspective of two international shippers, which were British shippers and Korean shippers. Hence, this study was comparative research, testing whether the shippers of the two countries were differently satisfied with the provision of service functions. Each shipper from those different countries showed different perspectives of logistics service performance and operations. Although both British and South Korean shippers received overall logistics service functions among different types of logistics providers, British shippers reported more satisfaction than South Korean shippers. Intermodal coordination, paying customs duties, and issuing bills of lading were especially identified as variant determinants showing the different preferences and performance among service providers. Unlike Kang and Kim (2009) and Koo et al. (2009), Lune et al. (2013) attempted to strengthen global seaborne trade while identifying which determinants can affect the demand for a container shipping service. Hence, the research conceptualized a demand chain paradigm and container shipping services as key enablers, and empirically verified the relevant linkages between demand chain management and container shipping-related variables, like services for profit maximization. It was concluded that the demand for shipping services clearly had a positive influence on the business activities of buying new or second-hand ships, and on the service capacity of the shipping industry. The implication of this study was that a shipping service model can identify the factors that collectively affect the service capacity in the shipping industry. For example, the effect of the demand for shipping services is much more correlated to capacity adjustment than the effect of freight rates on capacity adjustment. Accordingly, the findings revealed a great emphasis on managing and forecasting shipping demand, which is a critical step when making decisions on operations in the container shipping market.

Management. Many successful logistics companies can identify weaknesses in their supply chains so they can quickly take corrective actions and can have opportunities for supply chain improvement. Accordingly, it is vital to create, select, initiate, and manage appropriate key performance indicators (KPIs) to enhance their working process efficiently, and thus, achieve the company's goals. Relationship is also important because there are several supply chain entities with numerous variables chained up in one focal company. Therefore, Song et al. (2015) analyzed the relationship between KPIs and the decision variables, as well as the relationships among the KPIs, to evaluate the inside of a logistics company. Accordingly, they optimized the expected costs, service reliability, and shipping emissions under port-time uncertainty while incorporating into the operational level a joint tactical planning problem combined with the number of vessels, the planned maximum sailing speed, and the liner service schedule. After deriving a stochastic multi-objective optimization problem from experiments, the study could formulate the operational level criteria. As a result, there were mixed relationships given a set of KPIs with respect to three decision variables. Accordingly, they ran a multi-objective genetic algorithm (MOGA) method to illustrate the results and the application of the model, which was simulated by system dynamics, meta-heuristic optimization, and the MOGA method.

Relationship. Relationship has become a stronger requirement in fostering outsourcing decisions. Over the years, outsourcing has gained momentum in many industries because it mutually causes a synergistic effect when integrated successfully (Liu and Lyons, 2011). Hence, Santibanez et al. (2016) conceptualized a mathematical model given the condition of a non-cooperative supply chain network when internal logistics activities were outsourced to external logistics providers. The point was to find a decision process to maximize profitability from each layer of a network comprised of manufacturers, retailers, and logistics service providers without complete collaboration. This paper illustrated the model of a non-cooperative supply chain network in accordance with considerations of competition among logistics providers. Furthermore, the proposed model contributed to implications for determining the price level and logistics service quality with manufacturers, retailers, demand markets, and logistics service providers. An optimization model was applied to find an equilibrium pattern in the supply chain design model. Previously, a lot of research like that of Liu and Lyons (2011) studied logistics service quality from the perspective of individualistic countries, such as the service capabilities and performance of U.K. and Taiwanese 3PLs. However, Rahmat and Faisol (2016) investigated the cultural differences between individualistic countries and collectivist countries when valuing logistics service quality. Accordingly, their paper aimed to provide cultural elements with technical abilities in order to measure maximum satisfaction from Malaysian logistics service users. An experimental study revealed that the cultural context tends to have a strong bias toward better customer satisfaction, compared to performance-related factors. Additionally, the proposed framework conceptualized a theory of different elements of logistics quality for each cultural context. This paper clearly indicated that cultural context has a strong influence on making a decision about logistics service quality.

Infrastructure. There are many factors influencing the choice of a distribution network in supply chains. Infrastructure is one of the most prevailing factors that affect the function of a distribution network. In a sense, optimizing the flow of shipments is dependent upon how well the infrastructure can support it, or not. Additionally, different capacities for each distribution network location also add complexities to the choice of infrastructure. In order to manifest this aspect, Basligil et al. (2011) conducted research to find optimal routes for vehicles with different capacities at a lower cost. The application of infrastructure in a supply chain and logistics network is seen as a progression in integrated supply chain activities, such as network deployment, asset utilization, logistics costs related to lead time, and inventory in the supply chain. In previous studies, many researchers tried to optimize routing problems using mathematical models and heuristic algorithms. This paper expanded the scope of optimization by using a new mixed methodology in order to find an efficient distribution network at a low cost while meeting customers' demand. The authors used mixed integer programming by using GAMS 21.6/C-PLEX and a genetic algorithm by using C\#. 


\subsection{Differences from prior studies}

In the course of preliminary reviews, most of the studies and papers focused on development of a networkoptimization and cost-minimization model in the field of logistics services. However, there are not many studies and papers on evaluating logistics strategies and KPI components from the perspectives of finance and management. Furthermore, these two topics, such as establishing partnerships within supply chain entities and improving logistics efficiency in terms of government, are scarce. Even though several papers gave insights into the logistics attributes and criteria, the subject of the studies only included the entities of 3PLs and a limited scope of logistics attributes occurring in the logistics environment in Korea.

In contrast to the research previously reported, this study provides a more detailed analysis of each entity's preference in logistics service attributes. This study includes the survey results of entities in the supply chain, such as manufacturers and retailers. Furthermore, the target and the area of the survey were limited to Chinese people and Chinese companies, respectively, which differentiates the present study from the previous one.

\subsection{Methodology}

The analytic hierarchy process is a widely used measurement tool for dealing with complex and various scopes of problems (Vargas L. G., 1990). One of the distinctive features of AHP is that it can be flexibility integrated with decisionmaking on any topic corresponding to the respondent's comparison. This systematic approach is characterized by calculating weights for each element from multiple respondents, and gathering them collectively in order to rank them in order by weight (Lee et al., 2008).

Furthermore, the AHP model consists of goals and elements that can contribute to achievement. The AHP model is characterized as one hierarchy, because it encompasses a structure that can divide a goal into several components. It can arrange several components into a single homogeneous set (Teltumbde A., 2000). Decision making through the AHP consists of two steps: a hierarchical design process and attribute evaluation. Even though the AHP has a dependent problem, it is relatively proper for use in this study considering its wide range of application areas and different priorities for each entity in supply chains. In this regard, it is easy to allow multi-criteria decision making, and is applicable to a group decision-making environment.

In addition, our study entails hierarchical structuring to take greater account of the different priorities of each entity, which constitutes an important part of the decision process. In the hierarchy design stage, experience and knowledge of problem areas are required. In general, each person has a certain structural layer for their own problem solving. However, two different people can form the same hierarchical structure at the same time, because each one of them has a personal preference that can bring about different and various types of results.

The second stage is the evaluation stage for each attribute, which means comparing two attributes. Components from each hierarchical level are evaluated according to their importance and relevance to the contents (Vargas L. G., 1990). First, the usefulness of the AHP is to measure the ratio scale of the qualitative or intangible criteria, and the quantitative or typological criteria. Second, the AHP is effective at breaking down a big problem into smaller elements, and solving the problem by simply judging from a binary comparison.

In general, application of the AHP technique consists of five steps: (1) AHP model definition, (2) comparative judgment between related elements based on questionnaires, (3) a weight calculation technique, (4) composite weight calculation, and (5) alternative evaluation and analysis.

In this study, the main purpose is to redefine logistics service factors rather than evaluate alternatives to logistics services. Additionally, it is integral in this study to calculate the weight of each element, and compare several entities as a whole. Therefore, the AHP composite weight calculation was applied in this paper.

\section{Research approach}

The primary method used in the study was the analytic hierarchy process. The AHP evaluation criteria for the hierarchy of upper and lower factors were considered in order to analyze the preferred logistics service factors of each entity in the supply chain.

Several research papers have provided insights into selecting factors for AHP and structuring the hierarchy of factors and sub-factors in the study. Soh (2010) conceptualized the decision model for evaluating 3PL selection criteria. That model developed five stages, with each stage composed of a decision hierarchy: finance, service level, relationship, management, and infrastructure. Although these stages were adopted, the paper's exclusive focus on the components of each stage brought about the limited results that evaluated only 3PLs.

Expanding the concept and the scope of this study, compared to other studies, more sub-factors were exclusively selected and added to appropriately investigate the preferences of each supply chain entity. The extracted sub-factors were based on other preliminary research.

The group of survey respondents consisted of 78 people from 40 companies and government institutions in Shandong 
Province, China. In this study, four entities are grouped, and it is proper to have from 15 to 20 respondents per entity. The surveys were conducted from September 9 to November 11, 2016. There were eight associates, 49 managers, and 21 executives in the survey group from the four entities, and the lengths of their careers varied between 5 years and 30 years, segmented into time frames spanning every five years. Due to the scope of the research in Shandong Province being broad to a large extent and under different circumstances, the rationale for application of the methodology is different from a general statistical approach. With the advent of a fast-changing market environment, technological diversification in logistics services is growing at an unprecedented rate. Hence, the views and degree of understanding on a diverse range of logistics services by technology may differ, depending on the years of work experience (ranging from 5 to 30 years) in the field. Accordingly, various perspectives on this subject should be considered in order for these criteria to be assessed in a practical application.

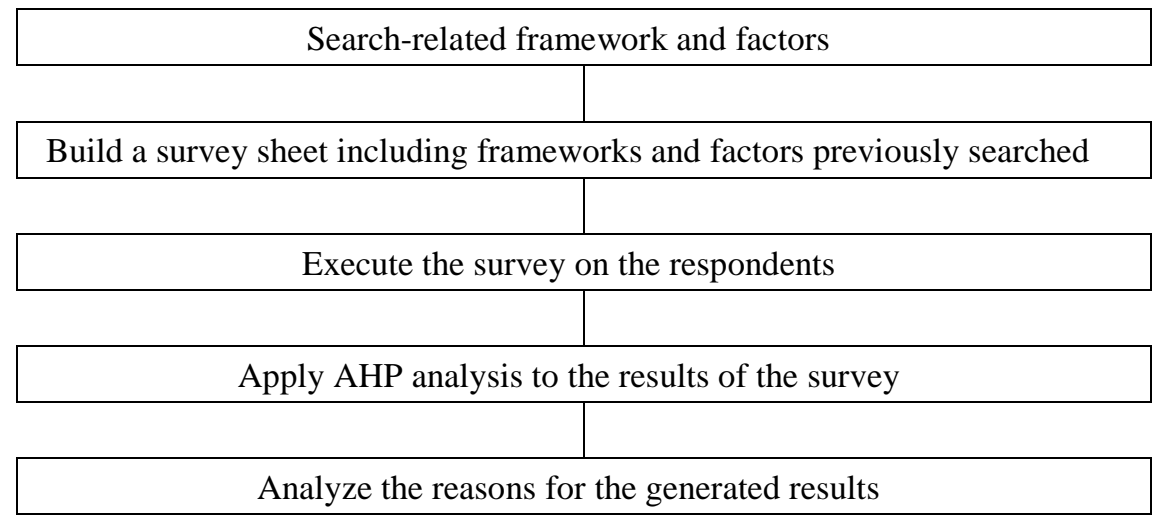

Figure 1. Research process in this study

\section{Empirical analysis}

Factors for the purpose of this paper were exclusively selected based on preliminary research. To analyze the preferred logistics services in this research, the AHP evaluation criteria for the hierarchy of upper factors (service criteria), lower factors (service traits), and service features considered are in Table 1.

First, Logistics Costs are composed of three distinctive factors: freight rates/pricing, warehouse rent, and tariffs. Financial Stability is indicative of credit-cash conversion. Reliability and Timeliness means on-time service; flexibility and responsiveness include three factors: door-to-door service, cross-docking, and modal shift. Frequency means time scheduling, routing, and linear shipping. Customization and Diversity are composed of three factors: diverse service option, project/special cargo, and cold-chain.

In addition, Convenience and Economies of Scale are indicative of lot-size/SKUs, master production scheduling, and international service network coverage. Transparency means tracking and tracing; Compatibility means partnership and information sharing. Benefit and Risk Share means sharing contacts, while Legislation means compliance, FTA/WTO, and different laws of logistics areas.

Performance Management means key performance indicators. Security and Safety means packaging/labeling systems and inspection. Reputation and Experience mean sustainability (HACCP, green logistics), company history, and credibility. Resilience means reimbursement (refunds, returns, and insurance), risk management/mitigation.

In addition, Logistics Manpower means the number of employees and their expertise. IT/IS Capability means sales communications devices (point-of-sale, electronic data interchange, enterprise resource planning), tracking/labeling codes (Radio Frequency ID tags, bar codes), item visibility. Space Capacity means transportation and container yard. Equipment Capability is indicative of gantry cranes, reach stackers, and automated storage and retrieval system (ASRS). 
Table 1. AHP evaluation hierarchy

\begin{tabular}{|c|c|c|c|}
\hline Service criteria & Service traits & Service features & Source \\
\hline \multirow[t]{2}{*}{ Finance } & Logistics costs & $\begin{array}{l}\text { Freight rate/ Pricing } \\
\text { Warehouse rent } \\
\text { Tariffs }\end{array}$ & $\begin{array}{l}\text { Plum et al. (2014)/ } \\
\text { Guericke and Tierney } \\
(2015)\end{array}$ \\
\hline & Financial stability & Credit-cash conversion & Zhang et al. (2015) \\
\hline \multirow{5}{*}{ Service Level } & Reliability and timeliness & On-time service & Soh $(2010)$ \\
\hline & $\begin{array}{l}\text { Flexibility and } \\
\text { responsiveness }\end{array}$ & $\begin{array}{l}\text { Door-to-door service } \\
\text { Cross docking } \\
\text { Modal shift } \\
\text { Chartering } \\
\text { On-demand scheduling } \\
\text { Rerouting } \\
\text { Expediting } \\
\text { JIT/JIS } \\
\text { CKD/ SKD }\end{array}$ & Soh (2010) \\
\hline & Frequency & $\begin{array}{l}\text { Time scheduling } \\
\text { Routing } \\
\text { Linear shipping } \\
\text { Periodical warehousing } \\
\text { EOQ }\end{array}$ & $\begin{array}{l}\text { Kim }(2009) / \\
\text { Koo et al. (2009)/ } \\
\text { Jiang et al. (2013) }\end{array}$ \\
\hline & Customization and diversity & $\begin{array}{l}\text { Diverse service options } \\
\text { Project/Special cargo } \\
\text { Cold chain } \\
\text { Fair/Art/Exhibition services } \\
\text { Value-added service }\end{array}$ & Zhang et al. (2015) \\
\hline & $\begin{array}{l}\text { Convenience and } \\
\text { Economies of scale }\end{array}$ & $\begin{array}{l}\text { Lot-size and SKUs } \\
\text { Master production scheduling } \\
\text { International service network coverage } \\
\text { Sorting/ Consolidation services }\end{array}$ & $\begin{array}{l}\text { Dong and Jing (2012)/ } \\
\text { Zhang et al. (2015) }\end{array}$ \\
\hline \multirow{4}{*}{$\begin{array}{l}\text { Relationship } \\
\text { (Extrinsic) }\end{array}$} & $\begin{array}{c}\text { Transparency } \\
\text { (Trust and fairness) }\end{array}$ & $\begin{array}{l}\text { Tracking } \\
\text { Tracing }\end{array}$ & Soh (2010) \\
\hline & Compatibility & $\begin{array}{l}\text { Partnership } \\
\text { Information sharing }\end{array}$ & Soh (2010) \\
\hline & Benefit and risk share & Risk sharing contract & Soh (2010) \\
\hline & Legislation & $\begin{array}{l}\text { Compliance } \\
\text { FTA/WTO } \\
\text { Documentation (Claims, L/C, B/L, Incoterms) } \\
\text { Certificate (ISO, Patent, Copyrights) } \\
\text { Customer clearance/ Brokerages } \\
\text { Different laws of logistics area }\end{array}$ & $\begin{array}{l}\text { Rajesh et al. (2011)/ } \\
\text { Rajesh et al (2012)/ } \\
\text { Rahmat and Faisol } \\
(2016)\end{array}$ \\
\hline \multirow{4}{*}{$\begin{array}{l}\text { Management } \\
\text { (Intrinsic) }\end{array}$} & Performance management & (1) & $\begin{array}{l}\text { Song et al. (2015)/ } \\
\text { Rajesh et al (2012) }\end{array}$ \\
\hline & Security and safety & $\begin{array}{l}\text { Packaging and labeling systems } \\
\text { Inspection (VGM, Dangerous goods, and Prohibited goods) }\end{array}$ & Soh (2010) \\
\hline & Reputation and experience & $\begin{array}{l}\text { Sustainability (HACCP) } \\
\text { Company history } \\
\text { Credibility } \\
\text { Expertise }\end{array}$ & Soh (2010) \\
\hline & Resilience & $\begin{array}{l}\text { Reimbursement (Refunds, Returns, Insurance) } \\
\text { Risk management and mitigation } \\
\text { Customer relationship } \\
\text { Management }\end{array}$ & Song et al. (2015) \\
\hline \multirow{4}{*}{ Infrastructure } & Logistics manpower & $\begin{array}{l}\text { The number of employees } \\
\text { Expertise }\end{array}$ & Soh (2010) \\
\hline & It/is capability & $\begin{array}{l}\text { Sales communication devices (POS, EDI, ERP) } \\
\text { Tracking/Labeling Code (Radio Frequency ID Tags, Bar Code) } \\
\text { Item visibility (Cloud-based Platform/ Dashboard- TMS, WMS) }\end{array}$ & Soh (2010) \\
\hline & Space capacity & $\begin{array}{l}\text { Transportation } \\
\text { Container yard } \\
\text { Warehouse } \\
\text { Rack } \\
\text { Hinterland }\end{array}$ & $\begin{array}{l}\text { Liu and Lyons (2011)/ } \\
\text { Zúñiga and Martínez } \\
\text { (2016) }\end{array}$ \\
\hline & Equipment capability & $\begin{array}{l}\text { Gantry crane } \\
\text { Reach stacker } \\
\text { Automated storage and retrievalsystem (ASRS) }\end{array}$ & $\begin{array}{l}\text { Liu and Lyons (2011)/ } \\
\text { Zúñiga and Martínez } \\
\text { (2016) }\end{array}$ \\
\hline
\end{tabular}


Table 2. Respondents' characteristics in Shandong Province, China

\begin{tabular}{ccc}
\hline & Entities & \# of Respondents \\
\hline & Total & 78 \\
Entity & 3PLs (Forwarder, Carrier, Warehouse) & 17 \\
& Customs (Airports, Seaports, Bonded areas) & 24 \\
& Market channels (Wholesalers, Retailers, E-retailers) & 22 \\
Position & Manufacturers & 15 \\
& Associates & 8 \\
& Managers & 49 \\
Career length & Executives & 21 \\
& $5-10$ years & 12 \\
& $10-15$ years & 26 \\
& $15-20$ years & 22 \\
\hline
\end{tabular}

In this section, the findings reflect the results of AHP analysis, which were divided into the five groups mentioned above. The preferred determination of logistics attributes for each group was analyzed to find which factors are preferred most for selecting a logistics service.

Table 3. Result of weight analysis: 3PLs (Forwarder, Carrier, Warehouse)

\begin{tabular}{|c|c|c|c|c|c|}
\hline Service criteria & Weight A & Service traits & Weight B & Overall weight $(\mathrm{A} * \mathrm{~B})$ & Ranking \\
\hline \multirow{2}{*}{ Finance } & \multirow{2}{*}{0.111} & Logistics costs & 0.514 & 0.057 & 11 \\
\hline & & Financial stability & 0.486 & 0.054 & 13 \\
\hline \multirow{5}{*}{ Service level } & \multirow{5}{*}{0.60} & Reliability and timeliness & 0.212 & 0.127 & 3 \\
\hline & & Flexibility and responsiveness & 0.185 & 0.111 & 4 \\
\hline & & Frequency & 0.154 & 0.092 & 5 \\
\hline & & Customization and diversity & 0.226 & 0.136 & 1 \\
\hline & & Convenience and economies of scale & 0.223 & 0.134 & 2 \\
\hline \multirow{4}{*}{ Relationship (Extrinsic) } & \multirow{4}{*}{0.241} & Transparency (Trust and fairness) & 0.248 & 0.060 & 10 \\
\hline & & Compatibility & 0.133 & 0.032 & 18 \\
\hline & & Benefit and risk share & 0.283 & 0.068 & 8 \\
\hline & & Legislation & 0.336 & 0.081 & 7 \\
\hline \multirow{4}{*}{ Management (Intrinsic) } & \multirow{4}{*}{0.228} & Performance management & 0.178 & 0.041 & 15 \\
\hline & & Security and safety & 0.164 & 0.037 & 16 \\
\hline & & Reputation and experience & 0.382 & 0.087 & 6 \\
\hline & & Resilience & 0.276 & 0.063 & 9 \\
\hline \multirow{4}{*}{ Infrastructure } & \multirow{4}{*}{0.161} & Logistics manpower & 0.353 & 0.057 & 12 \\
\hline & & IT/IS capability & 0.268 & 0.043 & 14 \\
\hline & & Space capacity & 0.165 & 0.027 & 19 \\
\hline & & Equipment capability & 0.214 & 0.034 & 17 \\
\hline
\end{tabular}

Inconsistency $=0.01$

First of all, the logistics service preference analysis of the 3PL group (Forwarder, carrier, warehouse) is shown in Table 3. As a result of analyzing the upper logistics service factors of the 3PL group, service level (0.60) was analyzed as the most important service factor. Relationship (0.241), Management (0.228), Infrastructure (0.161), and Finance (0.111) were stated as the other important service factors, in that order.

As a result of the overall weight analysis obtained by multiplying the upper service factor and the weight of each subservice factor, Customization and Diversity (0.136), Convenience and Economies of Scale (0.134), Reliability and Timeliness (0.127), Flexibility and Responsiveness (0.111) were analyzed as weighing in on the scale of importance in that order.

The 3PL group takes appreciation of service highly because they are entities that do not sell commodities directly, but sell a logistics service or a related service involving people, technology, and location working together to provide superior service for the customer's satisfaction. Additionally, their revenue generation is directly derived from the specialized service provisions, which bridge the gap between other business functions and logistics functions on behalf of customers.

The logistics service preferences of the customs group (airports, seaports, bonded areas) is shown in Table 4. As a result of analyzing the upper logistics service factors of the customs group, Relationship Level (0.288) was analyzed as the most important service factor. Next, the results were weighted in the following order: Management (0.277), Service Level (0.184), Infrastructure (0.153), and Finance (0.147). Overall weights were analyzed as falling into the following order: Benefit and Risk Share (0.094), Legislation (0.088), Reputation and Experience (0.087), and Resilience (0.086).

From the survey results, the customs group showed their strong bias toward relationship and management. Strategic alliances and management can come in different forms in any number of different countries with different combinations 
of suppliers, manufacturers, retailers, and customers. Furthermore, the customs group, involved in cross-border trade, requires not only appropriate actions to manage regulatory compliance, and appropriate plans, such as contingency, if necessary, but they also need cooperative help from other entities.

Additionally, the cultural context related to relationships is also important when it comes to meeting regulatory compliance. The customs group needs strategic relationships and management in order to formalize regulatory compliance to manage processes effectively and efficiently.

Table 4. Result of weight analysis: Customs (Airports, seaports, bonded areas)

\begin{tabular}{|c|c|c|c|c|c|}
\hline Service Criteria & Weight A & Service Traits & Weight B & Overall Weight $\left(\mathrm{A}^{*} \mathrm{~B}\right)$ & Ranking \\
\hline \multirow{2}{*}{ Finance } & \multirow{2}{*}{0.147} & Logistics costs & 0.500 & 0.074 & 5 \\
\hline & & Financial stability & 0.500 & 0.074 & 5 \\
\hline \multirow{5}{*}{ Service Level } & \multirow{5}{*}{0.184} & Reliability and timeliness & 0.120 & 0.022 & 19 \\
\hline & & Flexibility and responsiveness & 0.147 & 0.027 & 18 \\
\hline & & Frequency & 0.186 & 0.034 & 15 \\
\hline & & Customization and diversity & 0.177 & 0.033 & 16 \\
\hline & & Convenience and economies of scale & 0.370 & 0.068 & 7 \\
\hline \multirow{4}{*}{ Relationship (Extrinsic) } & \multirow{4}{*}{0.288} & Transparency (Trust and fairness) & 0.163 & 0.047 & 11 \\
\hline & & Compatibility & 0.208 & 0.060 & 8 \\
\hline & & Benefit and risk share & 0.325 & 0.094 & 1 \\
\hline & & Legislation & 0.304 & 0.088 & 2 \\
\hline \multirow{4}{*}{ Management (Intrinsic) } & \multirow{4}{*}{0.277} & Performance management & 0.169 & 0.047 & 12 \\
\hline & & Security and safety & 0.207 & 0.057 & 9 \\
\hline & & Reputation and experience & 0.315 & 0.087 & 3 \\
\hline & & Resilience & 0.310 & 0.086 & 4 \\
\hline \multirow{4}{*}{ Infrastructure } & \multirow{4}{*}{0.153} & Logistics manpower & 0.237 & 0.036 & 13 \\
\hline & & IT/IS capability & 0.211 & 0.032 & 17 \\
\hline & & Space capacity & 0.234 & 0.036 & 14 \\
\hline & & Equipment capability & 0.317 & 0.049 & 10 \\
\hline
\end{tabular}

Inconsistency $=0.01$

Table 5. Result of weight analysis: Market channels (Wholesalers, retailers, e-retailers)

\begin{tabular}{|c|c|c|c|c|c|}
\hline Service Criteria & Weight A & Service Traits & Weight B & Overall Weight $(\mathrm{A} * \mathrm{~B})$ & Ranking \\
\hline \multirow{2}{*}{ Finance } & \multirow{2}{*}{0.089} & Logistics costs & 0.511 & 0.045 & 10 \\
\hline & & Financial stability & 0.489 & 0.044 & 11 \\
\hline \multirow{5}{*}{ Service Level } & \multirow{5}{*}{0.185} & Reliability and timeliness & 0.158 & 0.029 & 16 \\
\hline & & Flexibility and responsiveness & 0.166 & 0.031 & 15 \\
\hline & & Frequency & 0.110 & 0.020 & 18 \\
\hline & & Customization and diversity & 0.180 & 0.033 & 13 \\
\hline & & Convenience and economies of scale & 0.387 & 0.072 & 5 \\
\hline \multirow{4}{*}{ Relationship (Extrinsic) } & \multirow{4}{*}{0.196} & Transparency (Trust and fairness) & 0.100 & 0.020 & 19 \\
\hline & & Compatibility & 0.134 & 0.026 & 17 \\
\hline & & Benefit and risk share & 0.246 & 0.048 & 9 \\
\hline & & Legislation & 0.520 & 0.102 & 2 \\
\hline \multirow{4}{*}{ Management (Intrinsic) } & \multirow{4}{*}{0.258} & Performance management & 0.128 & 0.033 & 14 \\
\hline & & Security and safety & 0.273 & 0.070 & 6 \\
\hline & & Reputation and experience & 0.299 & 0.077 & 4 \\
\hline & & Resilience & 0.300 & 0.077 & 3 \\
\hline \multirow{4}{*}{ Infrastructure } & \multirow{4}{*}{0.271} & Logistics manpower & 0.153 & 0.041 & 12 \\
\hline & & IT/IS capability & 0.249 & 0.067 & 7 \\
\hline & & Space capacity & 0.216 & 0.059 & 8 \\
\hline & & Equipment capability & 0.383 & 0.104 & 1 \\
\hline
\end{tabular}

Inconsistency $=0.01$

The logistics service preferences of the market channels group (wholesalers, retailers, e-retailers) is shown in Table 5. As a result of analyzing the upper logistics service factors of the market channels group, Infrastructure level (0.2712) was analyzed as the most important service factor. Next, the results were weighted in the following order: Management (0.258), Relationship (0.196), Service level (0.185), and Finance (0.089). Composite weights were analyzed as falling into the following order: Equipment Capability (0.104), Legislation (0.102), Resilience (0.077), and Reputation and Experience (0.077).

This survey result in the market channels group demonstrates that the issue is maintaining and improving competitiveness these days, and infrastructure has become an important factor for the group. The market channels group can take advantage of the new capacity by reconfiguring their logistics process and supply chain to improve service and reduce costs. Accordingly, a good infrastructure can impact the benefits and costs of the production, transportation, 
distribution, and retail processes, whether inside or outside the country.

Table 6. Result of weight analysis: Manufacturers

\begin{tabular}{|c|c|c|c|c|c|}
\hline Service Criteria & Weight A & Service Traits & Weight B & Overall Weight $\mathrm{A} * \mathrm{~B}$ & Ranking \\
\hline \multirow{2}{*}{ Finance } & \multirow{2}{*}{0.138} & Logistics costs & 0.548 & 0.076 & 5 \\
\hline & & Financial stability & 0.452 & 0.062 & 6 \\
\hline \multirow{5}{*}{ Service Level } & \multirow{5}{*}{0.135} & Reliability and timeliness & 0.286 & 0.039 & 11 \\
\hline & & Flexibility and responsiveness & 0.222 & 0.030 & 12 \\
\hline & & Frequency & 0.105 & 0.014 & 15 \\
\hline & & Customization and diversity & 0.290 & 0.039 & 10 \\
\hline & & Convenience and economies of scale & 0.096 & 0.013 & 16 \\
\hline \multirow{4}{*}{ Relationship (Extrinsic) } & \multirow{4}{*}{0.080} & Transparency (Trust and fairness) & 0.133 & 0.011 & 18 \\
\hline & & Compatibility & 0.060 & 0.005 & 19 \\
\hline & & Benefit and risk share & 0.148 & 0.012 & 17 \\
\hline & & Legislation & 0.659 & 0.053 & 7 \\
\hline \multirow{4}{*}{ Management (Intrinsic) } & \multirow{4}{*}{0.175} & Performance management & 0.107 & 0.019 & 14 \\
\hline & & Security and safety & 0.444 & 0.078 & 4 \\
\hline & & Reputation and experience & 0.148 & 0.026 & 13 \\
\hline & & Resilience & 0.301 & 0.053 & 8 \\
\hline \multirow{4}{*}{ Infrastructure } & \multirow{4}{*}{0.472} & Logistics manpower & 0.318 & 0.150 & 2 \\
\hline & & IT/ IS capability & 0.089 & 0.042 & 9 \\
\hline & & Space capacity & 0.319 & 0.151 & 1 \\
\hline & & Equipment capability & 0.244 & 0.115 & 3 \\
\hline
\end{tabular}

Inconsistency $=0.09$

The logistics service preferences of the manufacturers group are shown in Table 6 . As a result of analyzing the upper logistics service factors of the manufacturers group, Infrastructure Level (0.472) was analyzed as the most important service factor. Next, the results were weighted as falling into the following order: Management (0.175), Finance (0.138), Service level (0.135), and Relationship (0.080). Composite weights were analyzed as falling into the following order: Space capacity (0.151), Logistics Manpower (0.150), Equipment Capability (0.130), and Security and Safety (0.078).

In the 3PL, customs, and market channels groups, overall weights of the infrastructure were analyzed as being relatively low. In contrast, the overall weights for infrastructure in the manufacturers group were analyzed to be very high (ranked from 1 to 3). Undoubtedly, infrastructure is seen as a strong factor for the manufacturers group, from the above survey results.

From the perspective of the manufacturers group, they should take an integrative approach, upstream to downstream, enabling the flow of products in order to capture value and minimize costs. Accordingly, the manufacturers group needs appropriate infrastructures to enable the seamless flow of their products throughout the supply chains. For example, delayed raw materials or components can affect production scheduling upstream, which can incur losses ranging from several thousand dollars to even greater amounts. Downstream, the inventory in the production base also incurs great loss unless provided with an appropriate infrastructure. Accordingly, an appropriate infrastructure should be provided not only to avoid duplication of logistics activities but also to minimize inventory loss.

\section{Conclusion}

The purpose of this paper is to establish a backbone for evaluating a logistics service quality measurement tool that improves the quality of logistics services as a differentiating feature on behalf of customers. Therefore, it is important to take a different approach regarding the importance of logistics service attributes affecting the field of overall logistics entities, since many previous studies did not offer a holistic viewpoint integrating supply chain entities as a whole.

As the methodology for the study, AHP analysis was practically applied to analyze, categorize, and evaluate the survey results, allowing an easy description of circumstances and relationships. While admitting that the study does not include sophisticated optimization modeling, it has significant meaning because it suggests a new perspective on evaluating logistics service attributes for each supply chain entity. Thus, the study includes a selective process for categorizing supply chain entities and logistics service attributes in order to better evaluate causality between these constructs.

The results of this paper demonstrate the correlations between logistics service attributes and service preferences from each upper factor. Thus, the summarized results show the interrelated relevance of categorized logistics service factors. It is interesting to note that the study demonstrates distinctive service preferences for the analyzed results of five upper factors in each of the four entities - 3PLs (forwarder, carrier, warehouse), customs (airports, seaports, bonded areas), market channels (wholesalers, retailers, e-retailers), and manufacturers - regarding logistics service attributes.

Each upper factor has different perceptions regarding an evaluation of service preferences. For this reason, this paper provides different implications and discretions by following each entity's reliance on each factor. As previously 
mentioned in Section 4, the collated results based on the AHP method clearly indicate the differences in logistics service attributes, and between factors and evaluations of customers, which is worth further examination.

\subsection{Implications}

This paper proposes structured multiple criteria for selecting preferred logistics services. Based on the results of multiple criteria preference analysis, it is demonstrated that freight forwarders, 3PLs, and warehouse management agents have a higher degree of preferences in the service section that recorded all of the first to the fifth factors for professional logistics services. Service level occupied more than half of the total weight (0.60). Other important preferences include relationships within the supply chains, and management within the enterprise.

In particular, customers considered reputation and experience as a reflection of confidence in logistics services. As external reasons to support this assumption, the results of the analysis showed interest in risk sharing with other companies and in legislation from government agencies.

To ensure the speed and safety of customs clearance, customs officers heavily focus on streamlining the operational process, such as screening and regulatory compliance, and sharing risks with broad law enforcement authorities. The most dissatisfied aspect that Korean importers and exporters experienced in customs and bonded areas in China is that Japanese companies have a higher rate of filling out the required documents and processing patent documents, whereas Korean companies have a lower registration rate and slower work procedures. Furthermore, even if problems about the customs clearance of a product occur, Korean companies hardly ever receive quick and safe post-treatment.

Since shippers and logistics companies are sensitive to customs law and regulatory compliance, they consider the legal aspect the most important thing. Due to high competition among more than 100 ports available for customs clearance on coastal areas in China, and to produce higher revenues and container throughputs, the reputation and experience of those ports have become important factors for improving their competitiveness. Thus, these factors are becoming crucial for ports and customs clearance in recruiting qualified logistics companies and shippers.

The results show strong demand for quick handling of duty drawback and delayed work procedures in customs clearance. Additionally, they also present a strong interest in logistical costs and stability within a limited national budget. Since manufacturers transfer logistics functions to professional logistics companies, they long for the expertise in logistics personnel, manufacturing, and logistics space capacity, the efficiency of the equipment, and security/safety of logistics.

It is also noted that there is strong interest in logistics costs, because they account for a large portion of sales costs. Retailers tend to focus highly on the logistics characteristics of equipment utility, because they are aware of the importance of the efficiency level of equipment, which can put the product on the shelf from manufacturing and distribution facilities in the right place, at the right time, for the right cost. Hence, owning the right equipment utility is vital to ensuring the circulation of a picking/packing system that enables matching sales plans and customer demand.

In e-commerce business, legislation related to direct overseas buying and customs duty is becoming rigorous. Accordingly, a preference for resilience has been considered an important aspect of e-commerce, because it is considered essential to fulfilling customer refunds and reverse logistics processes in this area. The findings show that Chinese customers tend to consider reputation and experience before purchasing, because their purchasing ratio is closely related to e-commerce traffic and the seller's name recognition. As the number of large-volume business-to-business (B2B) customers increases, they show a tendency to prefer logistics attributes about economies of scale and convenience in order to save massive inventory and logistics costs.

\subsection{Limitations and future research}

The findings of the present study show the likelihood for developing a structured framework related to the relative importance of each factor's representations. However, this paper also has several limitations, which show the lack of providing much more objective and extended scopes for evidence of causality between these factors.

First, the number of survey respondents was limited to only 78 from 40 companies. It is necessary to have a larger pool of respondents in order to yield much more accurate results. Second, the regional scope of this survey is restricted to certain cities, such as Qingdao, Yantai, and Jinan, which are big cities in Shandong Province. Therefore, future studies will need to be conducted in more cities. Accordingly, further research needs more parameters regarding logistics service attributes considering constraints on resources in the examination process of a decision-making framework. Besides, it is necessary to compare the importance of logistics services recognized by Korean companies in China, and the preference of logistics services in China, in order to yield better results.

\section{Acknowledgments}

This research basically contains the contents of a master's thesis, "A study on preferred logistics service factors of each supply chain entity in China." A part of this paper was included in the proceedings of PUL (Port-city Universities League), a conference held in Incheon in 2017. 


\section{References}

Başligil, H., Kara, S.S., Alcan, P., Özkan, B., Çağlar, E.G., 2011. A distribution network optimization problem for third party logistics service providers. Expert Systems with Applications 38, 12730-12738.

Chin, F.C., Bae, J.H., Kim, G.O., 2007. A survey on the logistics service providers in Shanghai. International Journal of Physical Distribution \& Logistics Management 29, 588-605.

Domingues, M.L., Reis, V., Macário, R., 2015. A comprehensive framework for measuring performance in a third-party logistics provider. Transportation Research Procedia 10, 662-672.

Guericke, S., Tierney, K., 2015. Liner shipping cargo allocation with service levels and speed optimization. Transportation Research Part E: Logistics and Transportation Review 84, 40-60.

Jiang, Y., Shang, J., Liu, Y., 2013. Optimizing shipping-fee schedules to maximize e-tailer profits. International Journal of Production Economics 146, 634-645.

Kim, Y.D., 2009. An analysis of the measurement of the shipping service quality. The Asian Journal of Shipping and Logistics, 25 , 41-55.

Koo, J.S., Hwang, K.S., Yeo, H.J., 2009. Are shippers satisfied with the diversified provision of logistics service by shipping companies? -A study between the UK and South Korea. The Asian Journal of Shipping and Logistics, 25, 237-251.

Lee, K., Joshi, K., Bae, M., 2008. Using analytical hierarchy process (AHP) to identify the relative importance of the features needed for web-based systems development. Information Resources Management Journal 21, 88-100.

Liu, C.L., Lyons, A.C., 2011. An analysis of third-party logistics performance and service provision. Transportation Research Part E: Logistics and Transportation Review 47, 547-570.

Lun, Y.V., Lai, K.H., Wong, C.W., Cheng, T.C.E., 2013. Demand chain management in the container shipping service industry. International journal of production economics 141, 485-492.

Meng, Q., Wang, S., 2011. Liner shipping service network design with empty container repositioning. Transportation Research Part E: Logistics and Transportation Review 47, 695-708.

Plum, C.E., Pisinger, D., Salazar-Gonzalez, J.J., Sigurd, M.M., 2014. Single liner shipping service design. Computers \& Operations Research 45, 1-6.

Rajesh, R., S. Pugazhendhi, S., Ganesh, K., Ducq, Y., Koh, S.L., 2012. Generic balanced scorecard framework for third party logistics service provider. International Journal of Production Economics 140, 269-282.

Rajesh, R., Pugazhendhi, S., Ganesh, K., Muralidharan, C., Sathiamoorthy, R., 2011. Influence of 3PL service offerings on client performance in India. Transportation Research Part E: Logistics and Transportation Review 47, 149-165.

Santibanez-Gonzalez, E.D., Diabat, A., 2016. Modeling logistics service providers in a non-cooperative supply chain. Applied Mathematical Modelling 40, 6340-6358.

Song, D.P., Li, D., Drake, P., 2015. Multi-objective optimization for planning liner shipping service with uncertain port times. Transportation Research Part E: Logistics and Transportation Review 84, 1-22

Soh, S.H., 2010. A decision model for evaluating third-party logistics providers using fuzzy analytic hierarchy process. African Journal of Business Management 4, 339-349.

Teltumbde, A., 2000. A framework for evaluating ERP projects. International journal of production research 38, 4507-4520.

Vargas, L.G. (1990). An overview of the analytic hierarchy process and its applications. European journal of operational research 48, $2-8$.

Zhang, J., Nault, B.R., Tu, Y., 2015. A dynamic pricing strategy for a 3PL provider with heterogeneous customers. International Journal of Production Economics 169, 31-43.

Zúniga, R., Martínez, C., 2016. A third-party logistics provider: To be or not to be a highly reliable organization. Journal of Business Research 69, 4435-4453. 